\title{
PAPEL DELIMITADOR DO ARQUITETO E URBANISTA NA CONSTRUÇÃO DA PAISAGEM URBANA
}

\author{
Maria Victoria Marchelli ${ }^{1}$
}

Roberta B. F Squaiella ${ }^{2}$

\begin{abstract}
RESUMO
O presente artigo objetiva salientar o papel do arquiteto e urbanista na construção da unidade de paisagem urbana. O termo paisagem recebe diferentes conotações nas áreas da filosofia, da ecologia, da geografia e da arquitetura, tendo como conceito inicial a reflexão do homem na contemplação da natureza. Para isso, é construído o conceito de paisagem considerando a visão de Bartalini (2013), de que é necessário voltar as origens deste conceito, em que aborda-se a visão dos seguintes autores: Simmel (1913), o percursor e criador do conceito "Stimmung" - estado de alma; Dardel (1953), que compreende a relação entre o homem e a terra, destacando na paisagem a presença humana; e Ritter (1963), que a entende como sendo uma realidade esteticamente presente. Destaca-se que a paisagem precisa ser olhada, percebida e vivenciada pelo ser humano para tornarse uma unidade passível de significação. Nesse contexto, o arquiteto e urbanista surge como elemento importante na configuração urbana da paisagem. Considera-se que a integração entre ambos é importante para criar espaços urbanos com usabilidade e qualidade sustentável de vida urbana.
\end{abstract}

PALAVRAS-CHAVE: Paisagem. Arquiteto e urbanista. Espaços urbanos.

\section{DELIMITER ARCHITECT PAPER AND URBAN PLANNER IN CONSTRUCTION OF URBAN LANDSCAPE}

\begin{abstract}
This article aims to highlight the role of the architect and urban planner in the construction of the urban landscape unit. The term landscape gets different connotations in the fields of philosophy, ecology, geography and architecture, having as the initial concept, man's reflection in the contemplation of nature. For this, is built the concept of landscape considering the view of Bartalini (2013), that it is necessary to go back to the origins of this concept, through the vision of the following authors: Simmel

\footnotetext{
${ }^{1}$ Mestranda em Arquitetura e Urbanismo, Universidade Presbiteriana Mackenzie. Email: victoria.marchelli@gmail.com.

${ }^{2}$ Mestranda em Arquitetura e Urbanismo, Universidade Presbiteriana Mackenzie. Email: robssquaiella@gmail.com.
} 


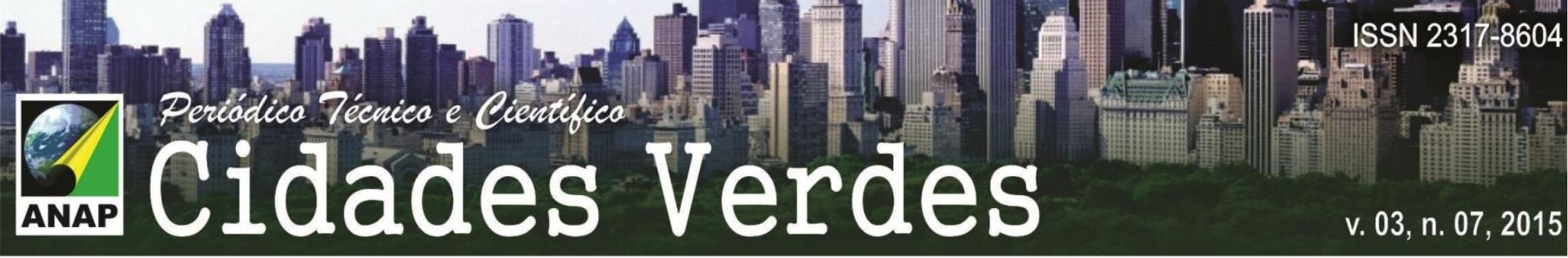

(1913), the precursor and creator of the concept "Stimmung" - state of mind; Dardel (1953), comprising the relationship between man and the land, highlighting in the landscape the human presence; and Ritter (1963), that understands it as an aesthetically present reality. It is noteworthy that the landscape needs to be looked at, perceived and experienced by the human being to become a unit capable of significance. In this context, the architect and urban planner emerges as an important element in the urban setting of the landscape. It is considered that the integration between the two is important to create urban spaces with usability and sustainable quality of urban life.

PALAVRAS-CHAVE: Landscape. Architect and urban planner. Urban spaces.

\section{PAPEL DEL ARQUITECTO DELIMITADOR Y URBANISTA EN CONSTRUCCIÓN DEL PAISAJE URBANO}

\section{RESUMEN}

Este artículo tiene como objetivo destacar el papel del arquitecto y urbanista en la construcción de la unidad de paisaje urbano. El término paisaje tiene connotaciones diferentes en los campos de la filosofía, ecología, geografía y arquitectura, teniendo como concepto inicial la reflexión del hombre en la contemplación de la naturaleza. Para ello, hemos construido el concepto de paisaje teniendo en cuenta la opinión de Bartalini (2013), que es necesario remontarse a los orígenes de este concepto, abordando la visión de los siguientes autores: Simmel (1913), el precursor y creador del concepto "Stimmung" - estado de alma; Dardel (1953), que comprende la relación entre el hombre y la tierra, destacando en el paisaje la presencia humana; y Ritter (1963), que la entiende como una realidade estéticamente presente. Es de destacar que el paisaje debe ser mirado, percibido y vivido por el ser humano para convertirse en una unidad capaz de significado. En este contexto, el arquitecto y urbanista emerge como un elemento importante en el entorno urbano del paisaje. Se considera que la integración entre los dos es importante para crear espacios urbanos con facilidad de uso y calidad de vida sostenible urbana.

PALAVRAS-CHAVE: Paisaje. Arquitecto y urbanista. Espacios urbanos.

\section{INTRODUÇÃO}

O conceito de paisagem como impressão da ação do homem surgiu no início do século XX (MASCARÓ, 2008). Nesse período, as cidades passaram por processos de urbanização desordenados que, até os dias de hoje, interferem na qualidade dos espaços urbanos. Mascaró (lbid, p.15) define a paisagem como "um espaço aberto que se abrange com um só olhar." O espaço se transforma de uma entidade natural para uma paisagem quando existe uma intervenção humana.

Salienta-se o fenômeno atual de que os elementos morfológicos que conformam a paisagem, como os edifícios, praças, entre outros, não se articulam 
entre si. Na maior parte das vezes, não existe uma unidade coerente que estabeleça vínculos entre eles e permita qualificar o espaço construído.

Conforme apontado por Bartalini (2013), é preciso voltar às "nascentes" para construir o conceito de paisagem, o que significa a retomada da dimensão estética, ou seja, da qualidade perceptiva e não da filosofia da beleza. Para isso, destacamse os autores Georg Simmel (1913), Eric Dardel (1953) e Joaquim Ritter (1963) que elaboraram as questões principais sobre a paisagem. Essa última diverge em diferentes conotações pelos campos da geografia, da filosofia, da ecologia e da arquitetura. Sua ideia é antiga e remonta a contemplação da natureza.

Esse trabalho objetiva evidenciar a importância e essência da unidade da paisagem para a configuração urbana, a partir da percepção humana. Destaca-se que os espaços construídos e públicos teriam usabilidade e qualidade, se as cidades fossem planejadas conjuntamente. Esses deixaram de ser apenas locais de circulação e passagem para tornarem-se locais de convívio, vitalidade e urbanidade.

É necessário criar espaços qualificados, pois a concentração de usos possibilita práticas mais sustentáveis em que o ambiente construído, ao se articular com o seu entorno e liberar espaços para uso público, forma parte da paisagem sem desarticula-la, nem "agredi-la”.

\section{SIMMEL}

Conforme apontado por Bartalini (2013), a primeira reflexão filosófica sobre o conceito de paisagem ocorreu no ensaio Filosofia da Paisagem (1913) do filósofo alemão Georg Simmel. Nele, aborda-se a natureza como "a cadeia sem fim das coisas, a criação e a aniquilação interruptas das formas, a unidade fluida do movimento de transformação, expressas pela continuidade da existência espacial e temporal" (SIMMEL, 2013, p.19).

A paisagem corresponde, na descrição simmelinana, a uma delimitação dessa natureza por meio da percepção do observador. Essa relação, entre o observador e a paisagem, é denominada de "Stimmung", conceito que pode ser traduzido para "estado de alma" (BARTALINI, 2013) e que através dele o ser humano molda a paisagem, transformando-a em uma unidade. Descreve-se que, 
[...] ela penetra todos os seus detalhes, sem que se possa atribuir a um só dentre eles a responsabilidade por isso: cada um participa da Stimmung da paisagem de uma maneira mal definível - e, no entanto, ao mesmo tempo em que ela não é exterior a estas contribuições, ela não é composta pela soma. (Ibid, p. 24)

Simmel (2013), por sua vez, estabelece uma analogia no seu texto para exemplificar o conceito de unidade:

[...] do mesmo modo que uma pilha de livros justapostos ainda não forma uma "biblioteca", mas se torna uma, sem que se retire ou acrescente um só volume, a partir do momento em que um certo conceito unificador a envolva para imprimir-Ihe uma forma.(Ibid, p. 21)

Pode-se dizer que a unidade de paisagem, para Simmel (2013), é uma síntese de objetividade e subjetividade. Ele parte de um objeto, elemento natural e, a partir da intervenção humana e da sua presença omnipresente, constrói-se a paisagem. Simmel, portanto, é pioneiro no conceito de paisagem considerando o papel do ser humano como elemento configurador e articulador do meio.

\section{DARDEL}

Eric Dardel (1953), no seu ensaio O Homem e a Terra, busca recuperar a relação, em termos geográficos, do homem com a terra. Seu ensaio é considerado como estando à margem dos outros geógrafos pois, focou-se na "questão do ser do homem" (BESSE, 2014).

Dardel compreende o espaço geográfico como sendo vivenciado e que constitui a experiência humana da terra. A paisagem é descrita como um conjunto, "uma convergência, um momento vivido. Um laço interno, uma 'impressão', une todos os elementos" (DARDEL, 2013, p. 100). Concordando-se com Bartalini (2013), Dardel sem fazer previa citação, remete a "Stimmung" de Simmel (2013), ao definir a paisagem dessa maneira.

Segundo Dardel, "a paisagem não é, na sua essência, para ser olhada, é a inserção do homem no mundo" (DARDEL, 2013, p. 100). A paisagem se unifica através de "uma tonalidade afetiva e dominante" permitindo ao ser humano 
conscientizar-se sobre seu habitat. Esse último, insere-se no termo "geograficidade" - a terra como "lugar, base e meio de realização" (Ibid, p. 100).

Dardel ganhou destaque no meio por destacar a presença humana, a partir do antropocentrismo. Se a terra é o local de existência do homem, no qual expõe seus sentidos e valores, também atua como cúmplice do mesmo.

\section{RITTER}

O ensaio de Joachim Ritter (1963), Paisagem. Função da Estética na Sociedade Moderna, apoia-se na discussão de dois textos para a distinção dos termos "natureza-objeto e natureza estética" (BESSE, 2014).

O primeiro deles, que inaugura o interesse moderno pela paisagem (FERRIOLO, 2013), trata-se da carta em que Francesco Petrarca relata a sua ascensão ao monte Ventoux, uma montanha nos Alpes franceses. Petrarca, em sua escalada, buscava atingir "à elevação da alma à felicidade" (RITTER, 2013, p. 47), apoiando-se nas teorias de São Agostinho, derivadas da Teoria do Cosmos, em que o mundo é compreendido pela "ordem do mundo". Seguindo a tradição filosófica, o mundo é contemplado mediante uma ordem divina e por meio de um ponto elevado. Dessa maneira, o espírito volta-se para o "Todo" e para o "divino" (lbidem).

Petrarca relata que tem dificuldades com a escalada, a qual apresenta-se desafiadora e o instiga a desistir. Ao chegar no cume, faz a leitura do texto Confissões de São Agostinho $^{3}$ e, em resposta ao mesmo, abandona a contemplação da paisagem, emancipando a natureza, para voltar-se a sua espiritualidade, seu interior. Petrarca encontra-se, portanto, em um debate interno, uma luta com seu estado espiritual. Dominado pela racionalidade, deixa de apreciar o "espetáculo da natureza" que se lhe apresenta e visualiza a natureza e, a paisagem como "fruto e produto do espírito teórico" (Ibidem).

\footnotetext{
${ }^{3}$ A passagem em destaque é: "E os homens vão admirar os cimos dos montes, as ondas do mar imenso, os vastos cursos dos rios, a costa do Oceano e o movimento dos astros, e se esquecem deles próprios." - São Agostinho - Confissões, X, 8,17.
} 
No entanto Ritter (2013), compreende a paisagem como sendo "a natureza esteticamente presente se mostrando a um ser que a contempla provando sentimentos". Isto significa que, "a paisagem, pois, só encarna a natureza para aquele que 'sai' em direção a ela (transcensus) para fazer parte deste ser 'exterior' da natureza e participar, por seu intermédio, do Todo que está presente nela e por ela" (Ibid, p. 53). Pode-se dizer que, para Ritter, a paisagem se forma quando ela é delimitada pelos olhos humanos.

No segundo texto, Ritter (2013) estabelece uma reflexão sobre o momento de mudança, em que a natureza transcende para seu estado sublime, a partir da leitura do poema de Schiller, $A$ Promenade ${ }^{4}$. Destaca que o homem, quando vivia no campo, tinha uma relação de subsistência com a natureza. Com a migração das pessoas para as cidades, ocorre o momento de "divórcio" entre a sociedade e a natureza. Essa quebra, ente ambos elementos, se caracteriza por ser responsável pela contemplação da paisagem. O homem, livre desse meio, aprende a apreciá-la e a dominá-la.

Como apontado por Bartalini (2005), esses textos representam que o ser humano é "lançado" no mundo para explorar a terra e que a sua característica investigativa é que o faz peregrinar em busca de respostas.

\section{O PAPEL DELIMITADOR DO ARQUITETO E URBANISTA}

Esses três ensaios sintetizam que o ser humano tem o papel de dominar a paisagem. Desde o primeiro ato, a percepção (estética), o homem se enquadra no espaço emergente, podendo intervir ativamente nela. Nesse contexto, apresenta-se o arquiteto e urbanista, o qual tem um papel predominante na paisagem urbana com a construção de edifícios, elementos morfológicos das cidades. $O$ arquiteto deixa seu traço, a delimita e, para abordá-la, precisa retomar a compreensão da unidade.

\footnotetext{
${ }^{4}$ Friedrich Schiller. A Promenade - poema de 1795 em homenagem a Rousseau.
} 
Nos dias atuais, predomina a falta de ligações entre os elementos novos e antigos e, mesmo dos próprios edifícios com o espaço urbano. O autor Christopher Alexander (1977) recorreu a caracterização de espaços exteriores, em negativos ou positivos. Os que são considerados positivos são aqueles que têm uma forma distinta e consolidada, se destacam das formas de edifícios que os rodeiam, mas estabelecem um diálogo com os mesmos.

Esses espaços positivos, ao terem designação, têm uso. A criação de espaços coerentes, com usos, deve-se a sua articulação com o entorno, para assim conformar elementos de qualidade na paisagem. A qualificação do espaço afeta o homem. Ele não só é responsável por ela como também apreciador. Quando os edifícios se localizam de tal maneira que o espaço resultante é apenas residual e amorfo, o espaço exterior considera-se negativo.

A busca por uma entidade "positiva" deve transcrever-se, também, na delimitação dos espaços internos dos edifícios para permitir a sua integração com os espaços circundantes (CHING, 1999). As permeabilidades, dentro dos edifícios, interferem nas positividades e na qualidade do espaço interno e urbano.

Ao planejar os espaços urbanos através da integração, parte-se do princípio da unidade. Olhando a cidade e sua paisagem como um todo, buscam-se soluções que objetivem qualificar os espaços. A qualidade perceptiva do homem é importante porque, a partir dos sentidos, conseguem-se extrair emoções, percepções.

Gordon Cullen (2009), compreende a paisagem urbana como responsável por tornar coerente e organizado, visualmente, o conjunto de edifícios, ruas e espaços que constituem esse ambiente urbano (paisagem construída). Objetiva entender que as paisagens estimulam reações emocionais nas pessoas, quando são percebidos.

Precisa-se considerar a qualidade perceptiva do homem na configuração de espaços, de maneira que nas concepções atuais, os espaços tenham vitalidade e urbanidade. A busca por esses elementos, caracteriza a prática de sustentabilidade da vida urbana. A partir de um espaço que os contenha, a cidade se desenha harmonicamente. 


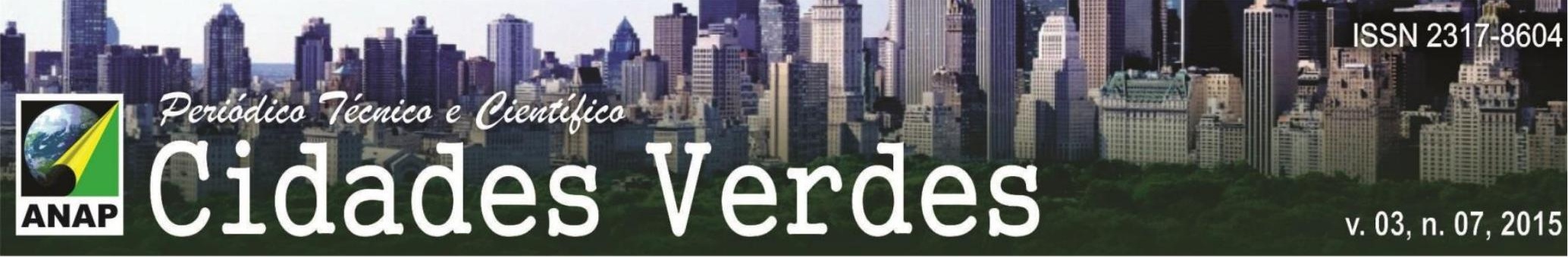

\section{CONSIDERAÇÕES FINAIS}

A partir da leitura dos ensaios de Simmel, de Dardel e de Ritter, entende-se que a formação da paisagem depende da interação do homem com o meio em que ele habita. Tal interação se dá pela observação, pelo uso e pela sensação que o espaço transmite. Assim, para que a paisagem seja consolidada como uma unidade é necessária a presença perceptiva e ativa do ser humano, que interage no espaço. Nesse contexto, o arquiteto e urbanista que planeja os espaços e, portanto, constrói a paisagem, precisa assimilar a estes um caráter sensível.

As cidades, por sua vez, estão em constante transformação e, para garantir organização e funcionalidade na configuração urbana, precisam funcionar como sistemas interconectados, nos quais estabeleçam-se relações entre seus membros. Dessa maneira, destaca-se a relação resultante entre o arquiteto e urbanista com a paisagem.

Nos desafios atuais das cidades, como a configuração e a concentração urbana, o uso de recursos naturais, impactos ambientais, entre outros, evidencia-se que a retomada pela qualificação do espaço, a partir da percepção e a atuação do arquiteto e urbanista, é necessária. Deve existir uma relação harmoniosa entre a sociedade e a natureza (habitat) e, por meio da interação e formação da unidade de paisagem, garantem-se melhores condições de sustentabilidade na vida urbana. Isso ocorre pois, esse processo incentiva o resgate dos espaços público e semipúblicos das cidades, que atualmente estão negligenciados.

Compreende-se, portanto, que a paisagem urbana é uma resultante da interação entre o espaço construído e o homem, sendo o arquiteto e urbanista um profissional responsável por criar espaços com qualidade e transformar a cidade vigente. 


\section{REFERÊNCIAS BIBLIOGRÁFICAS}

ALEXANDER, Christopher. A Pattern Language. Nova lorque, Oxford University Press, 1977.

BARTALINI, Vladimir. A Paisagem Vivenciada. In. Oculum (Campinas), Campinas-SP, v.04 p.117123, 2005.

Apresentação: A paisagem em arquitetura e urbanismo. São Paulo: Faculdade de Arquitetura e Urbanismo da Universidade de São Paulo, 2013 (Paisagem Textos).

BESSE, Jean-Marc. Ver a Terra. Seis ensaios sobre a paisagem e a geografia. Tradução de Vladimir Bartalini. São Paulo: Perspectiva, 2014.

CHING, Francis K. Arquitetura: forma, espaço e ordem. São Paulo: Martins Fontes, 1999.

CULLEN, Gordon. Paisagem urbana. Lisboa: Edições 70, 2009.

DARDEL, Eric. O Homem e a Terra: natureza de realidade geográfica (1953). São Paulo: Faculdade de Arquitetura e Urbanismo da Universidade de São Paulo, 2013. (Texto traduzido por Vladimir Bartalini com a finalidade exclusiva de subsidiar as disciplinas AUP5834 - A Paisagem no Desenho do Cotidiano Urbano e AUP5882 - Paisagem e Arte - Intervenções contemporâneas, do curso de pós-graduação da FAUUSP).

MASCARÓ, Juan Luis. Infra-estrutura da paisagem. Porto Alegre: Masquatro Editora, 2008.

RITTER, Joaquim. Função da estética na sociedade moderna. In: RAULE,G. Paysage, fonction de'l esthéthique dans la societé moderne (1963). São Paulo: Faculdade de Arquitetura e Urbanismo da Universidade de São Paulo, 2013. (Texto traduzido por Vladimir Bartalini com a finalidade exclusiva de subsidiar as disciplinas AUP5834 - A Paisagem no Desenho do Cotidiano Urbano e AUP5882 Paisagem e Arte - Intervenções contemporâneas, do curso de pós-graduação da FAUUSP).

SIMMEL, Georg. Filosofia da paisagem. In: SIMMEL, G. La tragédie de la culture eu autres essais. (1913). São Paulo: Faculdade de Arquitetura e Urbanismo da Universidade de São Paulo, 2013. (Texto traduzido por Vladimir Bartalini com a finalidade exclusiva de subsidiar as disciplinas AUP5834 - A Paisagem no Desenho do Cotidiano Urbano e AUP5882 - Paisagem e Arte - Intervenções contemporâneas, do curso de pós-graduação da FAUUSP). 